\title{
Assessment of health risks of exposure to hazardous chemicals by semi-quantitative method in a gas refinery complex
}

\author{
Samimi K, $\mathrm{MSc}^{1}$, Asiliyan $\mathrm{H}, \mathrm{PhD}^{2 *}$, Khasedar K, $\mathrm{MSc}^{3}$, Khavanin $\mathrm{A}, \mathrm{PhD}^{2}$ \\ 1- MSc of Occupational Health Engineering, Faculty of Medical Sciences, Tarbiat Modares University, Tehran, Iran. \\ 2- Associate Prof, Dept. of Occupational Health Engineering, Faculty of Medical Sciences, Tarbiat Modares University, \\ Tehran, Iran. 3- Head of Industrial Health Unit, Gas Refinery, Birjand, Iran.
}

\begin{abstract}
Received: December 2016, Accepted: February 2017

Background: Gas refining is a process in which workers are exposed to different chemicals. This study aimed to assess the health risks caused by exposure to these substances in order to determine hazardous jobs and to present controlling methods.

Materials and Methods: This cross-sectional study was performed on the workers at gas refinery in 2015. The sample included all the staff in operational parts and the selection was by census. To determine the risk of exposure to chemical pollutants, the method proposed by the Department of Occupational Safety and Health of Malaysia was used. Following this procedure, first the materials and processes were identified. Afterwards, risk and exposure rates were calculated. Using these two rates and risk rate formulas for individual chemicals, the exposure was calculated.

Results: The results showed that employees were exposed to 103 different types of chemicals that collectively were causing 162 types of exposure in different jobs. Of the total exposures, 5 percent were evaluated as "inconsiderable risk rate", 51 percent as low, 30 percent average, 13 percent high, and 1.2 percent as "very high risk rate".

Conclusions: The highest risk rate of exposure to chemicals in the refinery was related to benzene in stabilizer and topping area shift works $(\mathrm{RR}=5)$ as well as the shift works in feller area and evaporation pools with risk rate of 5, ranking their risk as very high, indicating that corrective actions should start on this hazardous and carcinogenic chemical as soon as possible.
\end{abstract}

Keywords: Risk Assessment, Hazardous Chemicals, Occupational Exposure

\section{Introduction}

Chemical pollutants in the workplace include gases, vapors, and solid and liquid particles. Excessive exposure to these substances in the workplace can cause poisoning and various diseases $(1,2)$. In the last fifty years, the number of factories producing chemicals has risen sharply, and new products are introduced into market each year. In 1942, the number of chemicals identified was about 600,000 . In 1947, the number reached some 4 million and is currently 78 million $(3,4)$. Also, there are a lot of chemicals that were previously considered as safe or low-risk for humans but were later regarded as carcinogens such as asbestos or thalidomide which causes genital disorder (5). Hazard refers to situations that have the potential of causing harm to people. Risk refers to the possibility of whether a hazard can harm a person or group at a certain point of time. Both hazards and risks can be expressed in words or numbers or any other meaningful way. What is obvious, at any rate, is that if there is no an exposure to hazards, there will not be any risk (6).

A main pillar of Health, Safety and Environmental (HSE) Management System is risk assessment where the goal is to identify, evaluate and control risk factors that influence the health and safety of staff in industry (7). In

\footnotetext{
* Corresponding author: Hassan Asiliyan, Dept. of Occupational Health Engineering, Faculty of Medical Sciences, Tarbiat Modares University, Tehran, Iran. E-mail: asilia_h@modares.ac.ir
} 
Occupational Health and Safety Assessment Series (OHSAS) 18001, risk assessment is defined as an evaluation process of risks caused by hazards in the workplace by considering controlling measures and deciding about their acceptability (8).

The purpose of chemical risk assessment is to identify potential risks of chemical substances, to assess workers' exposure to hazardous chemical substances, and to determine the risk of unintended deleterious effects on people as caused by contact with hazardous chemical substances $(9,10)$.

Without a way that can help to classify potential risks, costs and resources may be used in controlling risks that are of less priority at the expense of high-risk jobs (11). It is additionally required to evaluate health risks for proper decisions to be made concerning control and protection measures against complications of chemicals $(12,13)$. In other words, chemical health risk assessment can make it possible to do a comprehensive assessment of employees' exposure to hazardous health factors and make decisions about control measures and provision of care and education for the staff (14).

The semi-quantitative method of risk assessment of hazardous chemicals was first developed in 1994 by the Australian Commission on Safety and Quality in Health Care and was published by the Australian Government Publishing Service (13).
In 2000, a more complete version of this method was proposed by the Department of Occupational Safety and Health of the Malaysian Ministry of Human Resources (11). Singapore's Occupational Safety and Health Division then introduced it as a method of risk assessment of chemicals in this country (9).

Based on this method, Hunadia Husin and Abu Bakr Muhammad et al. (2010) evaluated the health risks of hazardous materials in the chemical and biochemical engineering laboratories (15).

Also, in a case study in the Iranian National Petrochemical Industry, Jahangiri and Parsarad evaluated the health risks caused by the chemicals in the industry through a semiquantitative method (14).

In another study, Golbabaei et al. assessed the health risks of exposure to chemical contaminants with an emphasis on the risk of leukemia in a petrochemical industry (16).

Another study was carried out by Jahangiri et al. in order to assess the health risks of exposure to chemicals in the polyurethane foam manufacturing industry by the mentioned method (17)

\section{Materials and Methods}

This cross-sectional study was performed on the workers at gas refinery in 2015. The sample included all the staff in operational parts selected by census (Table 1 ).

Table 1: The number of employees in working unit

\begin{tabular}{lc}
\hline \multicolumn{1}{c}{ Working unit } & Number of employees \\
\hline Water and steam & 21 \\
\hline Gas treatment & 5 \\
\hline Auxiliary operation unit & 18 \\
\hline Sales operation & 41 \\
\hline Maintenance and repairs & 160 \\
\hline Power house & 17 \\
\hline laboratory & 16 \\
\hline Consolidation and rectification & 8 \\
\hline General services unit & 98 \\
\hline
\end{tabular}


The method proposed by the Malaysian Department of Occupational Safety and Health was used to determine harmful chemical exposure risks, and procedure that was followed in this study is described below:

(A) Formation of a work group

According to this method, first a work group was formed whose members included the employer's representative (project supervisor) - occupational health specialist - and the head of the unit or his/her representative (11).

(B) Decomposition of the process into smaller tasks

Different industry departments and existing processes in each department and different jobs under each process were determined. Then the exact job description of the staff was extracted for which interviews were made, and documentation of organizational tasks were collected.

(C) Chemical identification

In the next step, all chemicals to which the working personnel might be exposed such as raw materials, intermediate materials, and main products and accessories were identified by observing the processes and checking process maps such as Process Flow Diagram (PFD) and Piping and Instrumentation Design (PID) and by examining chemical reactions and inventories lists. Afterwards, safety and health information of each of the substances was extracted using Material Safety Data Sheets (MSDS), container tags, and the information provided on the manufacturer's website was extracted. Based on this information, it was estimated whether and to what extent the materials could be hazardous.

(D) Hazard rate determination

According to the method recommended by the Malaysian Department of Occupational Health (11), the hazard rate of the identified chemicals can be obtained by lethal dose (LD50), lethal concentration (LC50), or toxic effects of chemicals. This information can be extracted from chemical health and MSDS and warning labels on chemical packages. After determining the risk numbers for each substance based on the above parameters, the largest number is selected as the hazard rate.

(E) Exposure rate

Exposure rate to chemicals can be calculated in two ways: (a) determination of actual exposure level for substances whose sampling and monitoring results were available. The exposure rate of 76 substances in different jobs was calculated in this way. For this purpose, a private company licensed by the Iranian Ministry of Health was called for to measure and estimate the availability level of some major chemicals, which were considered to be likely present in staff's breathing during the identification stage, (b) determination of exposure indices for substances for which the monitoring results were not available. The exposure rate of 76 substances in different jobs was calculated in this way. To determine staff exposure indices to a certain chemical, five criteria are involved each having five modes (9).

First criterion: steam pressure (in the case of gases and vapors) and particle size (in the case of dust)

Second criterion: the olfactory threshold contact limit (OT/PEL)

Third criterion: inventory control measures

Forth criterion: daily consumption of chemicals in kilograms or liters per week

Fifth criterion: duration of working with chemicals in terms of hours per week

(F) Determination of risk level

After determining hazard rate (HR) and exposure rate (ER), the risk rate (RR) for individual chemicals in all jobs was calculated according to the following formula or matrix table.

$\mathrm{RR}=\sqrt{\mathrm{HR} \times \mathrm{ER}}$

(G) Risk rating

The risk level of each chemical with exposure was extracted. Moreover, the chemical's risk rate was determined according to table 2 . This rating is in fact a basis to prioritize controlling measures for reducing exposures and chemical effects in the refinery. These actions can include technical and engineering measures 
such as process change or removal and replacement of dangerous substances, installation and upgrading ventilation systems as well as management measures like reduced exposure time through new rest-work shifts, rotational shifts, and finally, application of personal protective equipment.

Table 2: Risk rating

\begin{tabular}{cc}
\hline Rating & Risk rate \\
\hline Inconsiderable & $0-1.7$ \\
\hline Low & $1.7-2.8$ \\
\hline Average & $2.8-3.5$ \\
\hline High & $3.5-4.5$ \\
\hline Very High & $4.5-5$ \\
\hline
\end{tabular}

(H) Implementation of a corrective action plan Controlling and corrective measures were defined after determining the risk rate for chemicals exposure to which was estimated as high and very high.

(I) Documentation of evaluation

All evaluations were recorded in the forms numbered 1, 2a, 2b and 3. Thereafter, they were stored on the refinery HSE unit computer.

The points that should be considered in this method include:

- This method evaluates only health risks that threaten workers exposed to chemicals.

- This method specifies measures that should be taken after risk evaluation based on risk rates.

- In case the requested parameters are available, the method provides an indication of the relative risk. Nonetheless, the results may be questioned if reliable data are not available or if individualistic errors occur.

- This method cannot be used for those who are extremely sensitive to chemicals.

- This method only assesses risk of chemicals through inhalation exposure; skin and digestive contacts are not considered in this study (9).

\section{Results}

In this study, all refinery units were exactly examined. A total of 21 working processes including 58 job titles with 393 employees were identified which were exposed to 162 chemicals. Number 1, 2, and 3 forms were completed for this category of processes and tasks.

Five percent of workers' exposure to chemicals is of an "inconsiderable rate", while $57 \%$ is in "low rate", $30 \%$ in "average", $13 \%$ in "high", and 1.2 of a "very high" rate (Figure 1).

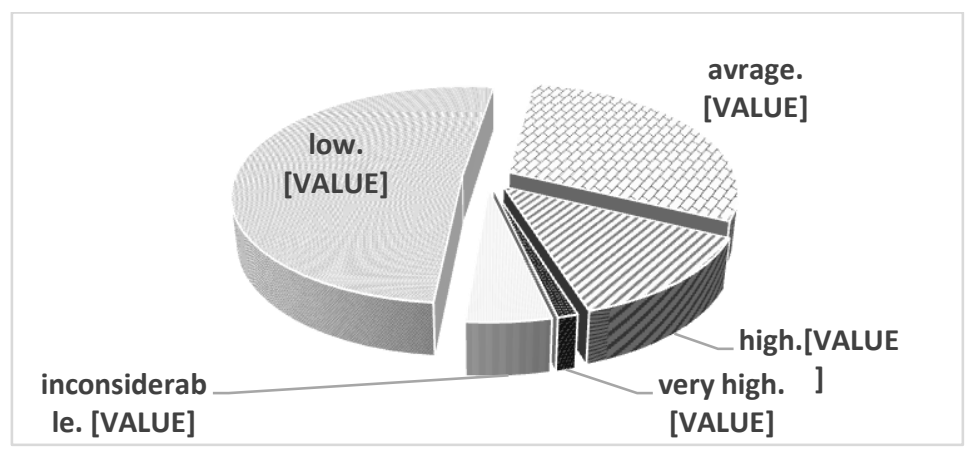

Figure 1: Gas refinery's chemicals risk rate 
In the steam and water unit, the highest risks were associated with phosphate (3.33), caustic (3.21), sulfuric acid (3.33), and inhibitor (3.13) all of which are in "average" risk rating. Among chemicals with exposure in the refinery unit, caustic (3.94), $\mathrm{H}_{2} \mathrm{~S}$ and benzene (3.16), and total dust (2.82) had the highest risk rating. Here, caustic's risk rating is "high" (Table 3), while the others are in "average".

Table 3: Jobs with "high" chemicals risk rate

\begin{tabular}{|c|c|c|}
\hline $\begin{array}{l}\text { Materials with "high" } \\
\text { chemical risk rate }\end{array}$ & Unit & Job title \\
\hline Caustic & Refinement & Dechlorination site man \\
\hline Sulfur & Auxiliary operation & Granular site man \\
\hline Sulfur & Auxiliary operation & 7and 8 Object packing and loading section \\
\hline Total dust & Sales operation & Adjustment operator \\
\hline Total dust & Sales operation & Fire man \\
\hline Total dust & Sales operation & Train operator \\
\hline Total dust & Sales operation & Loader driver \\
\hline Benzene & Sales operation & Loading section of petroleum liquids \\
\hline Benzene & Sales operation & Loading section operator \\
\hline Total dust & Sales operation & Formatting section shiftwork \\
\hline $\mathrm{H}_{2} \mathrm{~S}$ & Sales operation & Feller \\
\hline $\mathrm{Sn}$ and $\mathrm{Pb}$ fume & Maintenance unit & Electrical and instrument \\
\hline Thinner T445 & Maintenance unit & Blasting and painting \\
\hline $\mathrm{Sn}, \mathrm{Mn}, \mathrm{Si}$, and $\mathrm{Pb}$ fume & Maintenance unit & Welding \\
\hline $\mathrm{H}_{2} \mathrm{SO}_{4}$-benzene & Laboratory & Laboratory technician \\
\hline
\end{tabular}

Sn: Tin; Pb: Lid; $\mathrm{H}_{2} \mathrm{~S}$ : Hydrogen sulfide; Mn: Manganese; Si: Silicon; $\mathrm{H}_{2} \mathrm{SO}_{4}$ : Sulfuric acid

In subsidiary operations unit, solid sulfur and sulfur betonies (3.98), total dust and soil bentonite (3.46), and caustic (2.86) had the maximum risk numbers. Caustic and soil bentonite have an "average" risk rate and sulfur betonies is classified as "high" risk.

In the sales operations unit, total dust (4.47), benzene (3.16), $\mathrm{SO}_{2}$ (3.46), $\mathrm{H}_{2} \mathrm{~S}$ (3.87) were the most dangerous chemicals in this unit. Risk rates of benzene and $\mathrm{SO}_{2}$ were "average" and the others were "high". Exposure to amine in shift jobs of generators with the risk rate of
(3.1) was more hazardous than other chemicals in the power plant.

Major chemical risks in laboratory were related to sulfuric acid mist and benzene (4.47), nitric acid (3.46), and $\mathrm{SO}_{2}$ (2.82).

Exposures to benzene with the risk number (5), $\mathrm{H}_{2} \mathrm{~S}$ (3.16) and toluene (3) were the major risks related to chemicals in stabilizer and topping unit.

Occupational exposures to chemicals in the services unit were not evaluated as high health risk.

Table 4: The major chemicals health risk in the maintenance unit

\begin{tabular}{lc}
\hline \multicolumn{1}{c}{ Name } & Risk rate \\
\hline Silica & 4.47 \\
\hline Lead, tin and manganese fumes (in welding) & 3.87 \\
\hline Thinner (in blasting and painting) & 3.20 \\
\hline Lubricating oils & 3.40 \\
\hline $\mathrm{SO}_{2}$ & 3.29 \\
\hline Sulfuric acid mist & 3.05 \\
\hline Gasoline (in mechanical technician job) & 2.94 \\
\hline Tin and lead fumes (in electrical jobs and instrumentation) & 3.87 \\
\hline Water cutting (in lathe jobs) & 2.85 \\
\hline Gasoline (in machinery and taps) & 2.88 \\
\hline Calcium silicate (in insulation and lining jobs) & 2.96 \\
\hline
\end{tabular}

$\mathrm{SO}_{2}$ : Sulfur dioxide 


\section{Discussion}

Medical records and spirometry of the personnel, which belonged to two years ago, reported no proven cases of occupational diseases related to chemicals. However, it seems necessary to reexamine the medical status of workers.

Water and steam: Despite the fact that substances such as caustic, phosphate, sulfuric acid, and inhibitor with a high risk rate $(\mathrm{HR}=$ 4) were used in this unit, the risk rate of these substances were evaluated low as there is short-time exposure and low consumption during the week.

The highest risk levels were related to sulfuric acid (2.72) for shift jobs in open cooling towers enclosure and phosphate (2.22) in "industrial wastewater treatment superior shift job" where both substances were in low risk rate.

Gas treatment: Since chemicals are in a closed process in this unit, the major chemical exposures occur indirectly at the time of personnel sampling or accidental leakage, or from diffuse pollution in the forming unit, sulfur grading, holding point ponds, and incinerators, which are located in vicinity of this unit.

Exposure to caustic on the site dechlorination job is of a high risk rate due to its high risk $(\mathrm{HR}=4)$ and the amount of exposure rate (ER $=3.9$ ).

$\mathrm{H}_{2} \mathrm{~S}$ and benzene ( $\left.\mathrm{RR}=3.16\right)$ in dechlorination sections and Gas Treatment Unit (GTU) and Sulfur Recovery Unit SRU presented average risk rates, a fact which is justifiable given the sulfur recycling process and vicinity of the holding point ponds. Dust sulfur in SRU section with 2.82 risk number was also evaluated as of "average" risk. This is due to the proximity of SRU unit to forming and grading units.

Auxiliary operation unit: Exposure to chemicals in the wastewater treatment process is directly caused by charging chemicals. Although calcium hypochlorite and aluminum sulfate $(R R=2.72)$ were of relatively higher risks, the risk and exposure rates were similar in this unit and were evaluated as "low" risk rate.

Due to use and production of large volumes of granular materials, exposure condition is different in the grading unit from wastewater treatment unit. Bentonite soiled dust and graded sulfurs have created high exposure in almost the entire unit.

However, the situation in 7 and 8 object packaging and loading sections was different due to direct exposure to solid sulfur and betonies sulfurs. Given the "very high" rate exposure (3.97) in this section, the exposure risk was evaluated at a "high" level. This results from sulfur and bentonite sulfur packaging and weighing under an incomplete ventilation.

Sales operation: In the loading section of petroleum liquids, gas (3.87) presented a "high risk" rating for workers. In forming and feller parts, which may be called the most polluted parts of the refinery, different chemicals were measured and their risk numbers were calculated. Benzene (5) had the highest risk rating in the refinery, followed by $\mathrm{H}_{2} \mathrm{~S}$ (3.87) and sulfur dust (2.82) with "high" and "average" risk rates in shift feller area and evaporation pools, respectively. Exposure to sulfur dust in the case of sales operations' contractors presented a high risk rate (Table 4).

Maintenance and repairs: The highest risk rates were related to welding fumes, thinner, and industrial paints. Manganese fumes, tin, and lead with the risk number of 3.87 , silica particles (4.47), and thinner T445 (3.20) caused high risks for workers (Table 4).

Integration of some maintenance activities such as welding, steam, metal work, and power in one place resulted in sharing of pollution resource in the central workshop.

Power house: HB 100 and GTL 65 oils with the risk number of 1.7 had a "low" risk rate. Amine (3.10) presented an average risk rate for generators area shift. The higher risk number of amine is because of its high contact 
and exposure rate. Both in dosage and risk, amine was greater than other oils.

Laboratory: Exposure to $\mathrm{H}_{2} \mathrm{SO}_{4}$ and benzene (4.47) received the highest risk number, giving them a high rank. $\mathrm{HNo}_{3}$ (3.46) and $\mathrm{SO}_{2}$ (2.82) were evaluated as average, while other chemicals were considered as low risk.

What made risk assessment difficult in this section was failure to follow tasks based on organizational task description. All the personnel performed all the laboratory tasks, an issue which complicated the determination of exposure rates and reduced the accuracy of data.

Consolidation and rectification: The workers were exposed to $\mathrm{H}_{2} \mathrm{~S}$ and benzene with a high hazard rate (5). The highest risk rate was for benzene (5) with a very high risk rate. It was followed by $\mathrm{H}_{2} \mathrm{~S}$ and toluene (3.16 and 3 respectively) making them average in terms of risk rate.

In order to reduce health risks of exposure to chemicals in the refinery, recommendations include:

1. In chemical weighting and charging section, a local exhaust ventilation gets installed. Also, if possible and in coordination with suppliers, the chemicals get packaged such that they should not require weighting in water heater unit.

2. High exposure time and consumption volume of caustic in addition to its high risk rate require that local exhaust ventilation be installed in caustic charging place and exact medical examinations be applied to workers in this section. Other recommendations include replacement of caustic with a low-risk material or increased caustic granule diameter with an aim to prevent caustic particle suspension in charging time.

3. In addition to modification of ventilation systems and use of local exhaust ventilation, it is necessary in 7 and 8 object section to perform loading automatically without the presence of workers.

4. In oil loading part and sales operations' contractors, it is suggested that the exposure time be reduced by job rotation and job-rest system. In order to reduce chemicals risks, it is recommended to provide and use gas and steam masks, operator training, first-aid and emergencies guidelines, periodic monitoring of emissions, special medical monitoring, use of trucks and loaders with isolated cabins, and suitable air conditioning system, avoidance of loading in bad weather conditions.

5. Recommendations in maintenance and repair parts are as follows:

Installation of local exhaust ventilation in welding and power parts and precision instruments and carpentry; separation of carpentry and welding sections from valves and precision instruments unit; improvement of respiratory protection for welders and painters; personnel training concerning health risks of exposure to chemicals; and reevaluation of risks after the above-mentioned corrective actions.

\section{Conclusion}

The highest risk rate of exposure to chemicals in the refinery was related to benzene in stabilizer and topping area shift works $(\mathrm{RR}=$ 5 ) as well as the shift works in feller area and evaporation pools with risk rate of 5 , ranking their risk as very high, indicating that corrective actions should start on this hazardous and carcinogenic chemical as soon as possible.

\section{Acknowledgements}

Hereby, we express our gratitude to the managing director, research manager and HSE of gas refinery for their support in performing this study.

Conflict of interest: None declared.

\section{Reference}

1. McDermott HJ. Air monitoring for toxic exposures. $2^{\text {nd }}$ ed. Hoboken, New Jersey, United States: John Wiley \& Sons, Inc; 2004.

2. Phillip LW, Robert CJ, Stephen MR. Principles of toxicology: environmental and industrial 
applications. $2^{\text {nd }}$ ed. Hoboken, New Jersey, United States: John Wiley \& Sons, Inc; 2000.

3. Allahyari T. Risk analysis and risk assessment in chemical processes. $1^{\text {st }}$ ed. Tehran: Fanavaran Andishepajuh; 2005.

4. Falaki F, Farshad AA. Chemical safety. In: Hatami H, editor. Textbook of public health. $3^{\text {rd }}$ ed. Tehran: Arjomand; 2013.

5. Chris W, Neill HS. Occupational toxicology. $2^{\text {nd }}$ ed. Boca Raton, Florida, United States: CRC Press; 2004.

6. Mrtazavi B, Alizadeh Sh. Monitoring For Health Hazards at Work. $1^{\text {st }}$ ed. Tehran: Fadak Esatiz Publication; 2013. P.8.

7. World Petroleum Council. A roadmap to health risk assessment in the oil and gas industry, 2006. IPIECA Report. World Petroleum Council, London; 2006. Available from: http://www.world-

petroleum.org/resources/specialpublications/187-ipieca-reports

8. Det Norske Veritas Certication. Occupational Health and Safety Assessment Series (OHSAS 18001) \& Should I Care?. Managing Risk, DNV Certication, Inc. 16340 Park Ten Place, Houston, TX 77084; 2008. Available from: http://coss.net/Docs/cosm/StrategicPlanningan dProgEval/OHSAS18001Q\&A.pdf

9. Occupational Health Department. Guidelines on risk assessment for occupational exposure to harmful chemicals. Singapore, Ministry of Manpower; 2002. P.3-26.

10. karimi A, Jamshidi Slukoei HR, Eslamizad S. Designing SQRA as a software to semiquantitative chemical risk assessment in workplace. Journal of Occupational Hygiene Engineering 2014; 1(2):47-56.
11. Ministry of Human Resources. Assessment of the health risks arising from the use of hazardous chemicals in the workplace (A manual of recommended practice). $2^{\text {nd }}$ ed. Department of Occupational Safety and Health, Ministry of Human Resources, Malaysia; 2000.

12. Jahangiri M. Health risk assessment of occupational exposure to harmful chemical factors in the management system of health, safety, environment. Paper presented at: The $1^{\text {st }}$ National Conference on Safety Egineering \& HSE Management; 2005; Tehran, Iran.

13. National Occupational Health and Safety Commission. Guidance note for the assessment of health risks arising from the use of hazardous substances in the workplace (NOHSC: 3017). Canberra, Australian: NOHSC; $1994 . \quad$ Available from: http://catalogue.nla.gov.au/Record/384273

14. Jahangiri $M$, Motovagheh $M$. Health risk assessment of harmful chemicals: case study in a petrochemical industry. Iran Occupational Health Journal 2011; 7(4):18-24.

15. Hunadia Husin S, Mohamad AB, Sheikh Abdullah SR, Anuar N. Chemical health risk assessment at the chemical and biochemical engineering laboratory. Procedia Soc Behav Sci 2012; 60:300-7.

16. Golbabaie F, Eskandari D, Rezazadeh Azari M, Jahangiri M, Rahimi M, Shahtaheri J. Health risk assessment of chemical pollutants in a petrochemical complex. Iran Occupational Health Journal 2012; 9(3):11-21.

17. Jahangiri M, Jalali M. Health risk assessment of harmful chemicals in order to provide control guidelines: case study in polyurethane from industry. Occupational Medicine 2014; 5(4):33-41. 